Escuela de Ciencias Sociales y Humanidades, UNED, C.R. URL: http://investiga.uned.ac.cr/revistas/index.php/espiga/index ISSN: 1409-4002 • e-ISSN: 2215-454X

\title{
Jóvenes en prensa escrita costarricense: "Y si juntamos este montón de vagos con las drogas, es un tema serio» (sic)
}

\author{
Bryan Roberto Vargas-Vargas \\ https://orcid.org/0000-0002-1324-4421
}

Recibido: 22 de febrero, 2019 - Aceptado: 18 de julio, 2019

\section{RESUMEN}

El presente artículo aborda la discusión de las representaciones sociales sobre las personas jóvenes en la prensa escrita en Costa Rica. En detalle se desarrolla un análisis de las miradas desde las cuales se construye a las personas jóvenes, su reproducción en los medios de comunicación y las consideraciones de quienes reciben contenidos noticiosos sobre esta población. Es un estudio cualitativo con alcance descriptivo y tiene como fuentes primarias de información varios diarios digitales costarricenses con todos aquellos contenidos que versan sobre este grupo de población en un periodo de análisis entre 2015 y 2016. Se ahonda en la utilización del término «nini» en el desarrollo de las noticias y la producción de estereotipos que circundan este constructo por parte de quienes producen la información y en quienes la reciben.

Palabras clave: Juventud, medios de comunicación de masas, sociología de la comunicación, estereotipos, prensa de información diaria.

\section{Formato de citación según APA}

Vargas Vargas, B. (2019). Jóvenes en prensa escrita costarricense: «Y si juntamos este montón de vagos con las drogas, es un tema serio (sic)». Revista Espiga, 18 (38), 196-225.

\section{Formato de citación según Chicago-Deusto}

Vargas Vargas, Bryan Roberto (2019). «Jóvenes en prensa escrita costarricense: «Y si juntamos este montón de vagos con las drogas, es un tema serio (sic)». Revista Espiga $18,{ }^{\circ} 38$ (julio-diciembre, 2019): 196-225.

* $\quad$ Máster en Diseño Urbano, Universidad de Costa Rica. Sociólogo de la Universidad Nacional de Costa Rica y arquitecto-urbanista. Estudiante en la especialización Liderazgo, Cambio Climático y Ciudades, de FLACSO, Ecuador. Investigador social del Centro Agenda Joven de la Universidad Estatal a Distancia de Costa Rica desde el 2012. Intereses de investigación: juventud, ciudad, planificación urbana y territorial.Correo: bvargas@uned.ac.cr 


\section{Introducción}

El presente trabajo es un producto de investigación en el cual se busca establecer la comprensión que se tiene sobre las personas jóvenes en medios de comunicación ${ }^{1}$ escrita costarricense. Se dará énfasis a la utilización del término "nini» en el desarrollo de noticias, debido a su uso frecuente, el cual parece generar significados diversos en quienes reciben los contenidos. Este concepto, que enmarca a quienes «no estudian, ni trabajan», ocasiona una serie de interpelaciones superficiales producto de una caracterización ambigua, las cuales serán objeto del artículo.

En estudios previos sobre jóvenes y medios de comunicación en los que se utilizaba como categoría el término «ninis», Gutiérrez García y et al. ${ }^{2}$ sostienen que en el contexto mexicano se empezó a asociar peligrosamente a los jóvenes que estaban sin estudiar o trabajar con un grave riesgo de ser cooptados por asociaciones delictivas, incluyendo el crimen organizado. Según los autores, esta asociación entre actividades delictivas y «ninis» es reforzada por un discurso promovido por los medios periodísticos, la radio y la televisión que, a su vez, refleja el pensar de dirigentes y autoridades políticas e instituciones.

Estos mismos escritores señalan que existen dos tendencias predominantes que se muestran en los medios de comunicación sobre jóvenes, a saber: a) la primera vinculada con la falta de oportunidades educativas y laborales y b) una elaboración estereotipada en las cuales los jóvenes son situados como vagos, perezosos y pasivos, sobre todo insensatos en el cumplimiento de su responsabilidad social. Además, se ha evidenciado la frecuencia de este término en medios de comunicación y en las expresiones de dirigentes y políticos, así como en reportes científicos y propuestas de trabajo personal y social ${ }^{3}$.

En este artículo interesa dar respuesta a las siguientes interrogantes: ¿Por qué es importante trabajar la construcción mediática de las personas jóvenes en la prensa escrita costarricense? ¿Cuáles son los vacíos o comprensiones respecto de los jóvenes en la prensa escrita? ¿Qué recepción tienen los contenidos noticiosos sobre las personas jóvenes?

El artículo está compuesto por tres partes: 1) apartado metodológico, en el que se explica el proceso de investigación en el que se enmarca este artículo y el desarrollo propio de la reflexión; 2) apartado de análisis, subdividido en: reflexiones sobre el contexto social y las representaciones sociales, la introducción a la discusión sobre los «ninis», presentación de resultados de investigación y discusión desde los comentarios emitidos por los receptores de las noticias; y, por último, 3) un apartado de conclusiones generales.

1. Según la Real Academia Española, medios de comunicación se entienden como: «Instrumentos de transmisión pública de información, como emisoras de radio o televisión, periódicos, internet». Para este estudio, se utilizan únicamente los periódicos nacionales en formato digital.

2. Gutiérrez García, Raúl Alejandro et al., «Los jóvenes que no estudian ni trabajan en México», acceso: 04 de noviembre, 2019, www.redalyc.org/pdf/292/29238007007.pdf

3. Ibíd, 2 


\section{Metodología}

La investigación posee un enfoque cualitativo con un alcance descriptivo. Está orientada a un proceso para caracterizar a las personas jóvenes en la prensa según los atributos que los mismos medios aportan, busca alcanzar la comprensión sobre la juventud y sus representaciones en medios de comunicación a lo largo del tiempo.

La base documental completa de este artículo fue construida durante el 2016, además compila todos los contenidos que referencian a las personas jóvenes en los diarios digitales ${ }^{4}$ costarricenses entre 2015 y 2016. La base mencionada tiene una estructura interna con los siguientes ítems: a) título de la noticia, b) nombre del medio de comunicación, c) fecha de publicación, d) resumen de la noticia, e) tema de la noticia, f) sección de la publicación y g) localización territorial (nacional o internacional). El proceso de compilación de las noticias se realizó mediante un instrumento tipo cuestionario que se digitalizó en Google Forms, con el que se inició la búsqueda de noticias digitales desde diciembre de 2016 en retrospectiva, para finalizar con la pesquisa en enero de 2015. En la base se incluyen noticias, editoriales, entrevistas y artículos de opinión, entre otros, que en su encabezado o en su desarrollo hacen alguna referencia, directa o indirecta, sobre la población joven. Así se obtuvo un total de $725^{5}$ resultados, los cuales se distribuyen de la siguiente forma:

\begin{tabular}{lc}
\multicolumn{1}{c}{ Medio } & Porcentaje \\
CR Hoy & $43,3 \%$ \\
La Nación & $24,3 \%$ \\
La Prensa Libre & $18,2 \%$ \\
Diario Extra & $8,3 \%$ \\
Elpaís.cr & $3 \%$ \\
La República & $1,4 \%$ \\
La Teja & $0,6 \%$ \\
El Financiero & $0,3 \%$ \\
Semanario Universidad & $0,4 \%$ \\
\hline
\end{tabular}

Fuente: Elaboración propia. La base completa se puede revisar en el sitio web del Centro Agenda Joven en Derechos y Ciudadanía. ${ }^{6}$

4. Según el Centro de Investigación y Estudios Políticos citado por Mena Araya (2016), para el 2015 la ciudadanía costarricense que se informa a través de medios digitales había aumentado, con la televisión como la vía más utilizada para obtener información, mientras las redes sociales aumentan su presencia y las noticias en sitios de internet aumenta a $49,1 \%$, igualando el porcentaje a la gente que se informa por prensa escrita (física).

5. Se debe aclarar que el compilado agrupa las diferentes formas de presentar información que puede encontrar en un diario o semanario, por ejemplo: una redacción periodística, artículos de opinión, entrevistas, editoriales, ediciones especiales, entre otras. A lo largo del análisis se precisará la naturaleza de cada material; en este artículo en particular interesa identificar en la generalidad de la base de datos esos temas y espacios sociales en los que discute sobre las personas jóvenes. Desde el punto de partida del levantamiento de información, se asume que habrá temas recurrentes tomados de experiencias previas en investigación y teorías sobre juventud, esto no implicó mayor énfasis por compilar algunos temas sobre otros, pero sí un posicionamiento que considera que la población joven es en buena parte negada de derechos, tanto en Costa Rica como en otros países de Latinoamérica.

6. La base completa se puede encontrar en: http://investiga.uned.ac.cr/agendajoven/bases-de-datos/ 
Dos puntos son importantes en términos metodológicos: primero, la selección de los diarios responde, en primera instancia, a la viabilidad temporal de cubrir solo el periodo de los últimos dos años, para ese momento 2015 y 2016; y segundo, para compilar, se buscó en todos los diarios digitales de circulación nacional y en dos semanarios (El Financiero y Semanario Universidad), con el criterio de que tuvieran en su título o en su desarrollo alguno de los siguientes términos: juventud, joven, jóvenes, juvenil, persona joven, juventudes o «nini». No hubo especial atención sobre algún diario o semanario, a pesar de la diferencia en la periodicidad. Es decir, en términos metodológicos se trabajan las representaciones sociales de los siguientes modos operativos ${ }^{7}$ :

a. Modo semántico se aplica a los textos, un ejercicio de asociación libre de palabras, para obtener un material referido a objetos, sucesos, emociones y sentimientos; donde ocasionalmente se mencionan personajes-fenómeno de la personificación en la representación social.

b. Modo lexical considera sustantivos, verbos, adverbios, adjetivos, proposiciones y todas las expresiones gramaticales. En última instancia se busca en la reflexión el acercamiento al «modo cognoscitivo procesual, la representación social observa creencias, atribuciones de causalidad, estereotipos ${ }^{8}$, actitudesevaluaciones y tendencias de conducta».

De los ítems utilizados para la compilación, dos son los más importantes, a saber: el tema de la noticia y la sección de la publicación. Estos ítems responden a una revisión teórica y revisión sistemática de investigación sobre juventud, que mostraron precisamente temáticas, problemáticas y ámbitos sociales en los que se ha discutido sobre las personas jóvenes, lo que permitió delimitar campos que han demostrado tener relevancia cuando de las personas jóvenes se trata; sobre esto se profundiza al inicio del análisis.

Por otro lado, para el desarrollo del presente artículo, lo primero fue catalogar el total de la información compilada dentro de las miradas teóricas e institucionales, que se explicará más adelante, lo que permitió diferenciar y seleccionar aquellos temas y contenidos ajustados a los criterios de: a) reproducciones de las miradas institucionales de cómo se ha construido el objeto de la juventud en los medios escritos y b) los ámbitos donde la juventud se hace visible socialmente; ambas dimensiones desarrolladas por José Antonio Pérez Islas9.

Esta categorización se presenta más detallada en el apartado de análisis de resultados y será sobre estas noticias que cumplen los criterios antes dichos, con las cuales se hace el posterior análisis de recepción del mensaje.

7. María de Carmen Vergara Quintero, «La naturaleza de las representaciones sociales», Revista Latinoamericana de Ciencias Sociales, Niñez y Juventud, vol. 6, núm. 1 (enero-junio. 2008): 68, acceso: 04 de noviembre, 2019. http://biblioteca.clacso.edu.ar/Colombia/alianza-cinde-umz/20130801104940/ ArtMariadelCarmenVergara.pdf

8. Según el diccionario de la Real Academia Española, estereotipo es: «Imagen o idea aceptada comúnmente por un grupo o sociedad con carácter inmutable.»

9. José Antonio Pérez Islas, Ser joven en México: conceptos y contextos (México: Educación y Ciudadanía A. C., 2000), acceso: 04 de noviembre de 2019, http://www.educiac.org.mx/pdf/Biblioteca/Juventud_e_ Identidad/019SerJoven_en_Mexico.pdf 
El segundo momento de análisis es una deliberación que toma como base comentarios o réplicas de usuarios por medio de redes sociales en internet sobre algunas de las noticias que versan sobre jóvenes. Estas noticias, previamente valoradas en el apartado anterior $^{10}$, debían, en su título o desarrollo, contener información sobre los jóvenes que no estudian o trabajan, o explícitamente el término «nini». Para esta segunda parte, en la que se utilizan los comentarios realizados desde las cuentas personales de los usuarios, no se presentarán los textos literales y no se expondrá a la persona autora, por lo que se mostrará, a modo de tendencias, los que compilen el tipo de valoración o juicio. Es importante señalar que estos comentarios son propios de las personas usuarias y no son responsabilidad de los medios de comunicación, quienes además hacen manifiesto que para comentar, cada persona debe conectarse con su cuenta de red social personal (cada empresa de comunicación contiene su política de privacidad referente al acceso y uso de datos de sus usuarios).

El siguiente esquema resume el proceso del trabajo realizado:

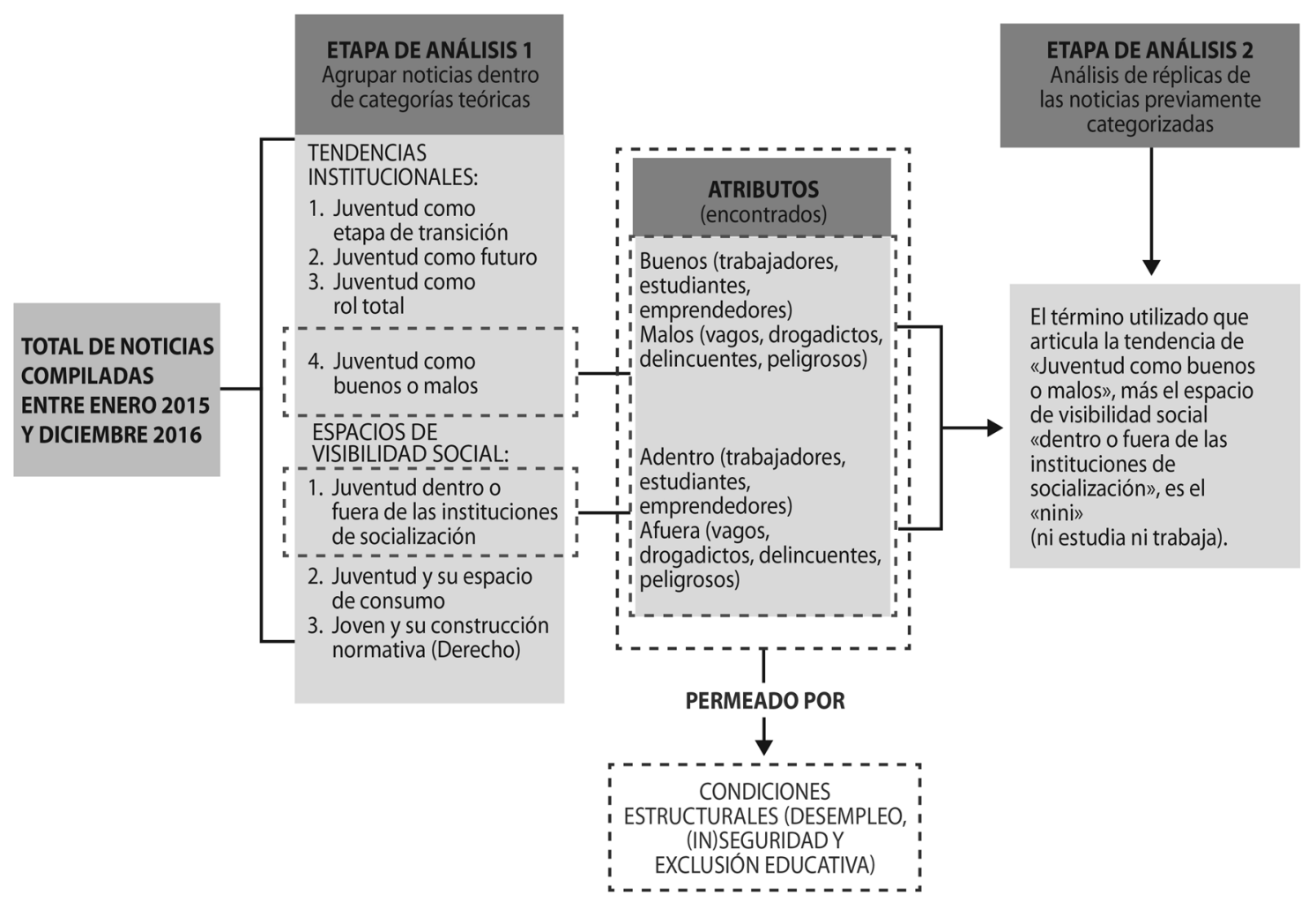

Figura 1. Procedimiento de análisis realizado en este artículo. Fuente: Elaboración propia.

10. Es de destacar que se encuentra una relación entre las tendencias institucionales de comprensión sobre la juventud, en especial como buenos o malos y los espacios de visibilidad social, como estar dentro o fuera de las instituciones de socialización, por lo que hay una atención particular en ese trato que se explicará en profundidad en el apartado de análisis. 
Como practica interpretativa, y recordando lo indicado sobre cómo alcanzar la comprensión acerca de la juventud y las representaciones sobre este sector de la población en medios de comunicación a lo largo del tiempo, se plantea, en esta primera experiencia, la contrastación del fenómeno de los jóvenes en la prensa escrita con otras personas autoras en el tema y la otra voz posible que existe en este caso, tales como los receptores ${ }^{11}$ de los contenidos, por esa razón se da la utilización de los comentarios sobre los contenidos.

Esto es una medida de validez y confianza ${ }^{12}$ que busca la imparcialidad y coloca a las partes involucradas en el fenómeno; la voz que está ausente es la de las personas jóvenes de las cuales se habla. De igual forma, se detalla el proceso seguido, la construcción de las categorías y se pone a disposición la base de datos para cualquier inspección o análisis. Las etapas semántica, lexical y cognoscitiva procesual resumen el proceso seguido para el compilado.

Sobre la validez interna, esta se alcanza al lograr puntos de saturación; es decir, frecuencia y consistencia de determinada idea que permitió agrupar en categorías en temas y cometarios. Por otro lado, la validez externa tiene que ver con la validación mediante la comparación con otras investigaciones, en este caso hay una triangulación de teoría de la comunicación, teoría sobre juventud y representaciones sociales.

\section{Análisis}

\section{El contexto para las personas jóvenes y las representaciones sociales}

Para este apartado es importante iniciar con los estados del arte existentes sobre el estudio de la juventud en Centroamérica y sobre el estudio de los medios de comunicación. En el primer caso, Núñez ${ }^{13}$ retoma el primer estado del arte elaborado por Braslavsky en 1989 e indica que hay frecuencia temática sobre la población como lo fueron: participación, salud, trabajo y educación. Desde el estado del arte del propio Núñez ${ }^{14}$, se apunta esta misma propensión que resume en cuatro puntos: a) la relación escuela y el mundo del trabajo, b) culturas juveniles, c) políticas públicas y d) violencia en dos dimensiones (criminalización/seguridad y conflicto/exclusión social). De los estudios existentes, confirma Zúñiga ${ }^{15}$, hay una tendencia culturalista que deviene de la Escuela Birmingham en autores como Reguillo, Feixa y Barbero, entre otros; además señala las otras dos tendencias, la psicologista, que considera la juventud como etapa transitoria, y la cepalina, que aglutina esta población en tanto sus capacidades productivas.

11. Es evidente que al considerar la voz de quien recibe el mensaje, se asume que son activos en el proceso de comunicación y que a su vez se reconfiguran en emisores; esto es claro en la teoría de la comunicación desde hace ya mucho tiempo.

12. Hay otras consideraciones de validación y confiabilidad que se explican en el texto como mostrar la perspectiva teórica, posición del investigador, se explican los criterios de selección, se explica el contexto, hay un registro sistemático que se pone a disposición (base de datos). A lo largo del artículo hay una discusión con los referentes teóricos y el contexto, que busca triangulación coincidentes o contrarias.

13. Pedro, Núñez, Las juventudes disputadas. Aportes para un campo en construcción (Argentina: Editorial de la Universidad del Rosario, 2015), 36.

14. Núñez, Las juventudes disputadas..., 44-54.

15. Mario, Zúñiga Núñez, Pensar a los jóvenes: Más allá de modelos o monstruos (Costa Rica: Departamento Ecuménico de Investigación DEI, 2010), 17. 
En relación con lo estudiado sobre los medios de comunicación, también en el caso centroamericano, Patricia Vega ${ }^{16}$ hace un estado del arte de las reflexiones académicas sobre los medios en Centroamérica de los años de 1980 a 2015. Se destacan resultados como la función particular de los medios en cada uno de los países, que en general hay frecuencia en ejes como la Guerra Fría, los conflictos armados internos, los procesos de paz y el crimen organizado. En todo caso, Vega señala que la región centroamericana despierta interés (académico y periodístico) debido a lo convulsa y desigual que ha sido.

Dentro de estas dificultades en la región, los conflictos armados y la necesidad de consolidar estados democráticos y fuertes y la lucha contra la pobreza y la desigualdad, buena parte de la población más afectada y excluida son las personas en edad joven. Es en este punto donde coinciden autores como Pérez ${ }^{17}, \mathrm{Vega}^{18}$, Centeno ${ }^{19}$, Lemus ${ }^{20}$, Aliaga Sáez y Escobar Monje ${ }^{21}$, Duarte Quapper y Littin Menz ${ }^{22}$, Mejía ${ }^{23}$ y Saintout ${ }^{24}$, entre otros; quienes consideran que los jóvenes comienzan a verse y exponerse como los protagonistas de todas las problemáticas sociales. Esto se justifica, en buena parte, en las acciones de mano dura tomadas por algunos países o en responsabilizar individualmente a las personas jóvenes de la exclusión de muchos de sus derechos.

Hay una perspectiva clara, esta es que en la región hay una disputa por estar dentro de algunos espacios (educativo, laboral, consumo, salud) y quienes logren estos campos serán reconocidos como sujetos, mientras las personas jóvenes excluidas serán individualmente responsabilizados de su condición. Señala Zúñiga ${ }^{25}$ que «la institucionalidad social para reproducirse y gobernar, necesita de modelos y monstruos, estos como proyecciones simbólicas para subordinar la justificación a la ley institucional».

Sumado a lo anterior, estos trabajos previos han demostrado la relevancia del estudio en algunos ámbitos como educación, empleo/desempleo y violencia como objeto

16. Patricia Vega Jiménez, «La investigación sobre comunicación en Centroamérica (1980-2015)» Anuario Electrónico de Estudios en Comunicación Social Disertaciones (2016): 117-138, acceso: 04 de noviembre, 2019, http://www.redalyc.org/comocitar.oa?id=511552709007

17. Pérez Islas, José Antonio, Teorías sobre la juventud. Las miradas de los clásicos (México: Editorial Porrúa, 2008).

18. Vega Jiménez, «La investigación...», 2016.

19. Rebeca Centeno Orozco, «Discursos públicos y construcción de ciudadanía: ¿poder de los medios de comunicación?», Orbis. Revista Científica Ciencias Humanas 10 (28-2014): 120-133, acceso: 04 de noviembre, 2019, http://www.redalyc.org/articulo.oa?id=70930408007

20. Leslie Lemus, «Guatemala: repensando el vínculo entre juventud y violencia en la posguerra», LiminaR, Estudios Sociales y Humanísticos XVI (2-2018): 45-59, acceso: 04 de noviembre, 2019, http://www.scielo. org.mx/scielo.php?script $=$ sci_arttext\&pid=S1665-80272018000200045

21. Felipe Aliaga y Gerardo Escobar, «El imaginario social del joven en Chile, una aproximación teórica al concepto del joven problema», Aposta. Revista de Ciencias Sociales (31-2006): 1-17, acceso: 04 de noviembre, 2019, http://www.apostadigital.com/revistav3/hemeroteca/aliaga2.pdf

22. Klaudio Duarte y Catalina Littin, Niñas, niños y jóvenes: Construyendo imágenes en la prensa escrita (Chile: Asociación Chilena Pro Naciones Unidas, 2002).

23. Julio Mejía Navarrete, «Medios de comunicación y violencia. Los jóvenes pandilleros de Lima», Espacio Abierto 14 (3-2005): 389-404, acceso: 04 de noviembre, 2019, http://www.redalyc.org/pdf/122/12214304. pdf

24. Saintout, Florencia, Los jóvenes en la Argentina: Desde una epistemología de la esperanza (Buenos Aires: Universidad Nacional de Quilmes Editorial, 2013).

25. Zúñiga Núñez, Pensar a los jóvenes...,57. 


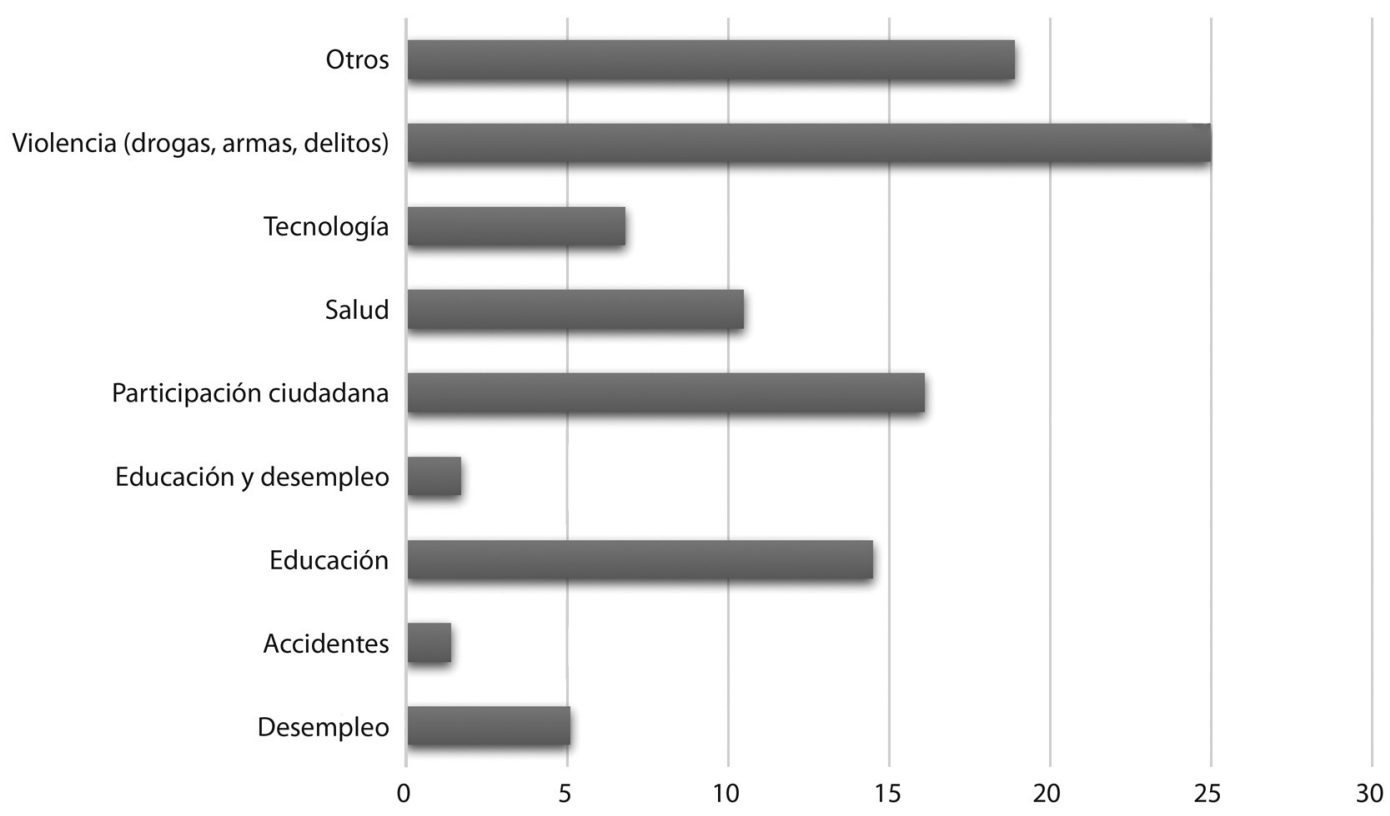

Figura 2. Costa Rica: Distribución de temas en prensa escrita, 2015-2016. Fuente: Elaboración propia.

científico y como producto mediático. La base propia en cuestión demuestra que de los 724 artículos de prensa escrita, el $25 \%$ de estas se discute sobre las personas jóvenes que cometen actos de violencia (en este caso se entendió así a los delitos contra la vida, drogas, crimen organizado y uso de armas).

En este punto interesa referir a las representaciones sociales. Los estudios revisados han mostrado una tendencia a segmentar a la población joven, como se muestra en el esquema de análisis (figura 1), hay espacios de visibilidad social tales como las instituciones $^{26} \mathrm{y}$ es trascendente estar insertos en estas, por ejemplo es determinante y es lo correcto para un joven, el acceso y permanencia en la escuela; de no estarlo, habrá otra institucionalidad que puede ocuparse de este, como puede ser la cárcel. Es una relación binaria que se traduce en cómo son comprendidas las personas jóvenes, los «buenos o malos» ${ }^{27} \mathrm{o}$ los «modelos o monstruos» ${ }^{28}$. Esto es de recalcar, ya que se está trabajando con información de diversa naturaleza (redacciones periodísticas, editoriales, entrevistas), pero que en todo caso habla de espacios sociales donde se ubica a las personas jóvenes.

A partir de lo anterior, lo que concierne es mostrar el posicionamiento teórico desde el cual se concibe este artículo y desde el cual interesa articular a la población en edad

26. Entiéndase institución como esos aparatajes propios de cualquier Estado, que tiene determinado fin con la cual mantener un determinado orden social.

27. Pérez Islas, Ser joven en México..., 5.

28. Zúñiga Núñez, Pensar a los jóvenes. 
joven con sus condiciones sociales; y, por tanto, ver los ámbitos sociales en los que los enmarca la prensa escrita, muy encuadrado en lo que Zúñiga ${ }^{29}$ llama juventud como «adjetivo», que califica personas, procesos sociales y espacios sociales.

En este sentido, la idea de Moscovici (citado por Vergara Quintero) sobre las representaciones como «teorías que permiten interpretar la acción cotidiana (imágenes, opiniones, actitudes, ritos, técnicas, costumbres, modas, sentimientos, creencias, miedos), tienen una carga importante en cómo clasificar los fenómenos y a las personas» ${ }^{30} \mathrm{o}$, en este caso, el grupo poblacional de interés, las personas jóvenes. Es por esto que la exposición del joven como problema social en prensa resulta importante de analizar, ya que esta será la «experiencia mediática» ${ }^{31}$ y representación que se tenga de este sector.

Las fuentes de este conocimiento son nuestras experiencias, y también las informaciones, los conocimientos y los modelos de pensamiento que recibimos y transmitimos a través de la tradición, la educación y, de una manera abrumadora en nuestro mundo globalizado, la comunicación social y las nuevas tecnologías de la información y la comunicación (TIC). De este modo, este conocimiento es en muchos aspectos socialmente elaborado y compartido. Con sus múltiples aspectos, este tipo de conocimiento intenta dominar nuestro entorno, comprender y explicar los hechos e ideas que pueblan nuestro universo o que surgen en él, actuar con otras personas o sobre ellas, situarnos respecto a ellas, responder a las preguntas que nos plantea el mundo, saber lo que significan los descubrimientos de la ciencia y el devenir histórico para nuestras vidas ${ }^{32}$.

A este nivel, es importante amalgamar lo dicho y entender la relación planteada, las representaciones que se tengan de un grupo social están estrechamente relacionadas con la comunicación y las imágenes, opiniones, actitudes, ritos, técnicas, costumbres, modas, sentimientos, creencias y miedos que se tengan, en este caso, con las personas jóvenes. Es por esto que este artículo tiene el interés de profundizar en estas representaciones, al ahondar en: cuando son «malos», con la utilización de términos como «ninis», vagos, drogadictos, peligrosos, vulnerables; o, por otro lado, cuando son «buenos» ${ }^{33}$ y pueden ser futuro, emprendedores, estudiantes, vigorosos.

29. Ibid., 20.

30. María de Carmen Vergara Quintero, «La naturaleza de las representaciones sociales», Revista Latinoamericana de Ciencias Sociales, Niñez y Juventud, vol. 6, núm. 1 (enero-junio, 2008): 55-80, acceso: 04 de noviembre, 2019, file://C:/Users/Bryan/Downloads/art\%C3\%ADculo_redalyc_77360103.pdf

31. Rojel Mayorga y Alberto, Carlos del Valle Rojas, «Análisis de la configuración semiótica de Chile y Perú en la prensa escrita», Quórum Académico 5 (1-2008): 17-40.

32. Vergara Quintero, «La naturaleza...», 64.

33. Pérez Islas, Ser joven en México..., 5. 
La discusión sobre «ninis» la presenta Borunda Escobedo ${ }^{34}$ como propia de un cambio paradigmático iniciado en la segunda década de los años dos mil ${ }^{35}$, momento donde se amalgama el constructo como categoría de análisis socio económico, pero que se le adhiere una connotación despectiva, no prevista hacia las personas entre 15 y 30 años que no han accedido a las instituciones educativas y a los mercados laborales. Este autor hace un compilado de utilizaciones de la palabra «nini», entre estos: a) la persona que desea trabajar y estudiar y que no tiene las condiciones para realizarlo y que es valorada como «nini»; b) la persona en edades de estar trabajando o estudiando y que no lo está haciendo como un todo; y c) la persona dentro de un rango de edad entre los 15 y menos de 30 años.

Según la Encuesta Nacional de Hogares en Costa Rica (2017), en el ámbito educativo, de cada 100 personas jóvenes, el $73 \%$ de estas obtiene como máximo la secundaria académica y solo un 19,4 \% posee algún pregrado o grado en educación superior. Sobre el desempleo abierto, que significa que buscaron trabajo en las últimas dos semanas de referencia y que están dispuestas a trabajar, esta misma población para el primer trimestre 2019, de cada 100 personas, el 10,1\% está desempleada. Las personas que están en otras formas de autoempleo o sub empleo, pueden aumentar este dato.

Es importante señalar que el rango etario de población entre 15 y 30 años se relaciona con la etapa de la juventud, por lo que se ha visto una semejanza al hablar de jóvenes y «ninis», se ven como equivalentes. Borunda expone también las ideas de José Manuel Valenzuela, quien valora que pueden existir al menos dos tipos de «ninis»: «ninis ricos» $\mathrm{y}$ «ninis pobres». Los primeros son aquellos en edad de estudiar y trabajar que tienen los recursos económicos y oportunidades para realizarlo y no lo hacen, mientras los segundos son aquellos en edad de estudiar y trabajar sin el recurso y posibilidades para acceder a estos espacios que, en todo caso, deberían ser caracterizados como excluidos y desempleados.

En el peor de los casos, expuesto por el mismo Borunda, cualquier acción, incluso delictiva, de una persona que no estudia ni trabaja, es tipificada como «nini», sin diferencia alguna de otro sujeto excluido del sistema educativo y condición de desempleo. Sobre esta misma idea, Dautrey ${ }^{36}$ da otros contenidos importantes en estos significados del «nini», en estos se incluye a todas aquellas personas que se escapan o son excluidas de las instituciones que representan el orden social, «que se coligan con la violencia y con actividades delictivas».

34. Borunda Escobedo, José Eduardo, «Juventud lapidada: el caso de los ninis», Nóesis. Revista de Ciencias Sociales y Humanidades (2013), 124, acceso: 04 de noviembre, 2019, http://www.redalyc.org/articulo. oa? id $=85927875006$

35. Según el autor, la sociedad mexicana a la cual pertenece, antes de esta década el que no estudiaba de inmediato engrosaba el mercado laboral, por lo que no explicaría la duplicidad de este término, escenario que cambia a partir del 2010 aproximadamente, donde existen grupos de personas que no están accediendo a ninguno de los dos ámbitos sociales.

36. Dautrey, Philippe; «La invención de una categoría: los NiNis. El caso mexicano», RIPS. Revista de Investigaciones Políticas y Sociológicas, julio-diciembre (2014), 104. 
Duatruy vuelve a un periodo económico anterior e indica que después de la década de 1980, los Estados sufrieron fuertes ajustes estructurales y, por tanto, su incidencia hacia la sociedad mediante las instituciones que daban estabilidad y que en algún momento integraban a los jóvenes en actividades productivas, se vino a menos en su alcance; esto se dio paralelamente con un señalamiento del individuo por su condición. Esta es una lectura de tipo estructural donde el autor hace responsable de la existencia de los «ninis» a una política económica en la cual los jóvenes asumieron el costo de la opción y donde cada uno se debe resolver o ingeniárselas para su existencia, según su capital inicial (cultural o económico).

Este constructo ha tenido trabajo desde las diferentes disciplinas de las ciencias sociales, las cuales han tratado de dar contenido y, sobre todo, un abordaje crítico y trascender la supuesta categoría que «alcanza» y homogeniza a todo un grupo que no estudia ni trabaja. Un ejemplo es la mutación del término que realiza Téllez Velasco ${ }^{37}$, en el que quiere hacer referencia a los profesionales jóvenes que tienen licenciaturas universitarias y tienen posgrados y que no consiguen trabajo, a los que denomina «titi»: «ti»enen licencia y «ti»enen posgrados. Esta es una realidad particular de jóvenes que ya no están estudiando y no están trabajando, que es diferente de jóvenes en un escenario sin educación superior y, además, desempleados.

El Estado de la Nación de Costa Rica del 2016 discute sobre la cuestión, pero con un cambio de perspectiva bajo los conceptos de exclusión educativa y laboral de la población de 15 a 24 años en Centroamérica; esto mediante un estudio que revela que 2,1 millones de jóvenes en la región están excluidos de estos ámbitos. Un señalamiento pronunciado por parte del Estado de la Nación es que este sector de la población es heterogéneo en su composición, por ejemplo: mujeres jóvenes de zonas rurales que se dedican a las labores domésticas a las cuales no se les considera que realicen un empleo formal o un joven en trabajos precarios como consecuencia de la nula formación académica. Señala el mismo estudio que la región pasa por un proceso de transición demográfica y tiene flujos crecientes de población joven, en edad laboral; esa problemática tenderá a agudizarse si no se implementan políticas para lograr una mayor inserción y permanencia, tanto en el sistema educativo como en seguridad laboral y remuneración justa.

Es importante referirse al principal autor tomado en cuenta para el desarrollo de este artículo, José Antonio Pérez Islas, quien elabora estudios sobre tendencias institucionales y ámbitos de donde se hace visible a la juventud. Seguidamente se muestra la relación entre dichas tendencias en los ámbitos en los que encajan las condiciones de quienes están excluidos del sistema educativo y laboral, los mal llamados «ninis»; para ello se procede a la presentación de los resultados.

37. Téllez Velasco, Daniel, «Jóvenes nini y profesionistas titi: la estratificación letrada del desempleo», El Cotidiano, septiembre-octubre (2011), 83-96, acceso: 04 de noviembre, 2019, http://www.redalyc.org/articulo.oa?id=32519776009 


\section{Resultados}

Como fue señalado en la introducción y en la metodología, se desarrollarán dos apartados en el análisis: el primero es una presentación de los resultados de las noticias seleccionadas que fueron valoradas dentro de los constructos teóricos de Pérez Islas, mientras el segundo es la reflexión que toma como referencia los comentarios producidos en las noticias que versan sobre «ninis».

\section{Presentación de los resultados de las noticias}

En este se muestran: a) reproducciones de las miradas institucionales de cómo se ha construido el objeto de la juventud por parte de los medios escritos; y b) los ámbitos donde la juventud se hace visible socialmente. Estos constructos son una elaboración de Pérez $^{38}$, quien a su vez hace una subdivisión de las miradas y ámbitos.

Respecto a las miradas institucionales (a), se hace una subdivisión de cuatro principales tendencias con las cuales se generaliza a las poblaciones jóvenes.

La primera es la consideración de la juventud como una etapa de transición; es decir, como momento de transformación hacia un mejor escenario o hacia la etapa adulta. Ilustrando la tendencia de la juventud como transición, en temas de salud y educación; los siguientes contenidos apuntan:

a. La etapa de la adolescencia es una época de muchos cambios, que marca la transformación de niño a adulto; muchos creerían que es un período donde no hay otra preocupación más que disfrutar la vida, pero la realidad es otra. De acuerdo con un análisis de la Asociación Costarricense de Adolescencia y Juventud, la depresión moderada y severa, las preocupaciones que incluso causan insomnio, tristeza y desesperación prolongada, son tan solo algunos de los problemas que esta población está sufriendo. ${ }^{39}$

b. «En aquel entonces, sí se sentía como un grado de respeto de estudiantes hacia profesor (...) ellos conocen de derechos, pero de deberes muy poco. ¡El estudiante hace lo que le da la gana!», afirmó el subdirector. ${ }^{40}$

c. Lo que pasa es que, al menos desde mi óptica, es cada vez más frecuente observar familias donde los derechos de los niños y niñas son el pan de cada día, pero los cumplimientos de deberes básicos están ausentes en el menú de la educación. ${ }^{41}$

38. Pérez Islas, Ser joven en México..., 5.

39. Rojas, Lady, «Resentimientos, desamores y bullying hacen a los jóvenes caer en depresión y tristeza», CR Hoy, 05 de diciembre, 2013, acceso: 05 de noviembre de 2019, https://archivo.crhoy.com/ resentimientos-desamores-y-bullying-hacen-de-los-jovenes-personas-deprimidas-y-desesperadas/ nacionales/

40. Cabezas, Yaslin, «Educadores "maniatados" ante rebeldía de niños y jóvenes», CR Hoy, 20 de octubre, 2015, acceso: 05 de noviembre, 2019, https://archivo.crhoy.com/ educadores-maniatados-ante-rebeldia-de-ninos-y-jovenes/nacionales/

41. Moreira, A. «Opinión: La educación de los hijos, derechos y deberes», CR Hoy, 02 de febrero, 2016, acceso: 05 de noviembre, 2019, https://archivo.crhoy.com/opinion-la-educacion-de-los-hijos-derechos-y-deberes/ opinion/el-lector-opina/ 
De las referencias mostradas, interesa apuntar la relatividad con la que se construye la cotidianidad de las personas jóvenes, ya sea en el espacio educativo donde las autoridades consideran que los derechos de las personas jóvenes son una dificultad en el proceso educativo (que antes no existían y que no deberían tener) o ya sea afrontando sus problemas de salud en una etapa que debería ser de goce. Es decir, la juventud como transición son todas aquellas consideraciones que por un lado señalan que en esta etapa no debe haber sufrimientos, enfermedades, problemas, derechos y, por otro, que se constituirán como persona en la etapa adulta.

La segunda tendencia elaborada por Pérez dentro de las miradas institucionalizadas y que comparte mucha relación con las consideraciones de las personas jóvenes como etapa de transición que se mostraron anteriormente, es la juventud como futuro; es decir, relativizar todas las necesidades y oportunidades que requieren las personas jóvenes, al considerar que estas deben ser cubiertas en una etapa adulta, que su oportunidad será en otro momento y que pueden ser violentados sus derechos porque es joven. Un ejemplo en el tema de salud y la relativización de las necesidades de las juventudes, se describe a continuación.

Un artículo del diario La Nación ${ }^{42}$ titulaba: «País tiene en abandono la salud mental de sus adolescentes». El texto pone sobre la mesa el deterioro en la atención de las personas jóvenes que tengan la necesidad de servicio en el área de salud mental. Señala además, que según la Organización Mundial de la Salud, el $45 \%$ de los problemas de salud que tienen las personas entre los 10 y 45 años, son trastornos mentales y, paradójicamente, el país ha visto reducida la atención a esta población, situación que se advirtió desde el 2008 en el sexto Informe del Estado de los Derechos de la Niñez y la Adolescencia. Marco Díaz, psiquiatra a cargo del Programa Integral de Atención del Adolescente, consultado para la realización de dicha nota, afirma que: «(...) además, los adultos suelen calificar los problemas de los jóvenes como insignificantes o pasajeros, menospreciando la potencial gravedad de estos. De ahí que muchos jóvenes han tratado de suicidarse o lo han hecho, y nadie se dio cuenta».

Lo importante, según el interés del presente desarrollo, es que la nota en sí habla de la relación entre las personas jóvenes y el tema de la salud; pero además, el contenido propio menciona la desatención hacia este grupo, a pesar de que existe evidencia de la constancia de enfermedades mentales sobre la población en edad joven; es un enviar al futuro esta u otra necesidad.

La tercera tendencia que interesa recapitular, la cual es la comprensión de la juventud como buenos o malos, es decir, esa lógica que trae intrínseca, por un lado el control (mediante instituciones) y, por otro, el desinterés sistemático por este grupo poblacional, designado en cada individuo la construcción de su propia realidad; es decir, idealizarlos desde dos extremos como personas que cumplen con las normas sociales esperadas o los contrarios.

42. Ross, Amy, «País tiene en abandono la salud mental de sus adolescentes», La Nación, 31 de agosto, 2013, acceso: 05 de noviembre, 2019, https://www.nacion.com/ciencia/salud-mental-de-los -ninos-y-los-adolescentes-esta-en-abandono/YLREUZS2IFHHXOEDEHLKQU64FE/story/ 
Al ilustrar la tendencia de la juventud como buenos-malos, los siguientes encabezados noticiosos apuntan:

- «Jóvenes intoxicados, incidente frecuente en festejos populares $»^{43}$

- «Con rompope, vino y cerveza, jóvenes ingresan al mundo del alcohol» ${ }^{44}$

- «Tras el licor y marihuana, jóvenes usan medicinas como droga» ${ }^{45}$

- «Un video compartido en Facebook muestra cómo varios jóvenes amarran una tortuga baula a un vehículo y la arrastran por varios metros» ${ }^{46}$

En ese sentido, es frecuente encontrar material desde estos opuestos donde los malos serán quienes, por ejemplo, se vinculan con el consumo de drogas, al desempleo, quienes no estudian; mientras que los buenos son aquellos que estudian, poseen empleo o son emprendedores. Los contenidos que se pueden introducir en esta tendencia son constantes, el material noticioso que relaciona a las personas jóvenes con drogas, violencia o como población en riesgo, son bastos.

$\mathrm{Al}$ ahondar en la tendencia, uno de los titulares señala: «Padres sufren viacrucis para rehabilitar a hijos adictos» ${ }^{47}$. Este artículo periodístico problematiza la relación entre juventud y consumo de drogas, y acentúa el interés de la discusión sobre las dificultades de rehabilitación, el costo y prolongación para los entes estatales dedicados a la atención de esta problemática y (des)controles sobre los centros privados de atención.

En otro artículo, «Tratamiento de la adicción juvenil» ${ }^{48}$, se problematiza, una vez más, el vínculo entre juventud y consumo de drogas. El texto se desarrolla sobre el fácil acceso de las personas jóvenes a las drogas lícitas e ilícitas y la repercusión del crimen organizado dedicado al narcotráfico en la sociedad. Sobre la idea de jóvenes buenos, esta se retomará más adelante.

La cuarta tendencia de comprensión es la de los jóvenes y sus roles totales. El rol total es la lectura que se hace desde un único rol social, tales como ser gay, punk, anarquista o

43. Barquero, Karla, «Jóvenes intoxicados incidente frecuente en festejos populares», CR Hoy, 25 de diciembre, 2015, acceso: 05 de noviembre, 2019, https://archivo.crhoy.com/ jovenes-intoxicados-incidente-frecuente-en-festejos-populares/nacionales/

44. Ugarte, Joselyne, «Con rompope, vino y cervezas jóvenes ingresan al mundo del alcohol», CR Hoy, 21 de setiembre, 2015, acceso: 05 de noviembre, 2019, https://archivo.crhoy.com/con-rompope -vino-y-cerveza-jovenes-ingresan-al-mundo-del-alcohol/nacionales/

45. Ugarte, Joselyne, «Tras el licor y marihuana, jóvenes usan medicinas como droga», CR Hoy, 05 de octubre, 2015, acceso: 5 de noviembre, 2019, https://archivo.crhoy.com/tras-el-licor-y-marihuana -jovenes-usan-medicinas-como-droga/nacionales/

46. Cascante, Sharon, «Jóvenes amarran y arrastran tortuga baula en Limón», La Prensa Libre, 29 de marzo, 2016, acceso: 05 de noviembre, 2019, http://www.laprensalibre.cr/Noticias/detalle/63217/ video:-jovenes-amarran-y-arrastran-tortuga-baula-en-limon

47. Avalos, Ángela, «Padres sufren viacrucis para rehabilitar a hijos adictos», La Nación, 21 de setiembre, 2015, acceso: 05 de noviembre, 2019, https://www.nacion.com/el-pais/salud/ padres-sufren-viacrucis-para-rehabilitar-a-hijos-adictos/JR5NTEM4FNGLBCI6565XD36ZUQ/story/

48. «Tratamiento de la adicción juvenil», La Nación, 22 de setiembre, 2015, acceso: 05 de noviembre, 2019, https://www.nacion.com/opinion/editorial/tratamiento-de-la-adiccion-juvenil/ORIQNXR6KVGA PJDYQZJIYQG7TI/story/ 
metalero, es decir, la arista única que no los considera más allá de una estética o rol que los define y determina. Los siguientes encabezados noticiosos ilustran la tendencia de la juventud como rol total:

- «Joven gay logró ser padrino de su sobrina $»^{49}$

- «Mercado no siempre entiende forma de ser de los adolescentes y desaprovecha sus compras en 'tribu'» ${ }^{50}$

- «Seguidores de Iron Maiden comienzan a acampar para el concierto» ${ }^{51}$

- «Publicación en Facebook contra bandera indigna redes sociales» ${ }^{52}$ (Esta noticia hace alusión a jóvenes anarquistas, quienes quemaron una bandera de Costa Rica.)

Esta tendencia del rol único que al parecer determina al sujeto joven (gay ${ }^{53}$, punk, anarquista, metalero), es una construcción simplista por no trascender en la complejidad de los sujetos, comprendiéndoles únicamente un rol total, totalizador y homogeneizador que no considera otros ámbitos como ser estudiante, padre de familia o trabajador. En el análisis, se verán comentarios sobre algunas de estas noticias, que muestra que la producción de una noticia con un juicio sobre un grupo de personas, tiene como consecuencia la generación de estereotipos, acusaciones y señalamientos por parte de quienes reciben el mensaje. Sobre esto, se verá la utilización del término «nini».

Las noticias ya descritas comienzan a dar indicios sobre cuáles son las construcciones, vínculos, problemáticas y contextos en los que se incluye a las personas jóvenes y dan pie para continuar con los ámbitos donde a las juventudes se le ha hecho visible colectivamente (b)..$^{54}$

Nuevamente Pérez da tres espacios donde se hace presente el debate. El primero son las instituciones de socialización, es decir, sobre la permanencia o exclusión del sistema educativo, el sistema laboral o la comunidad; la siguiente selección ayudará a desarrollar la idea:

49. Recio, Patricia, «Joven gay logró ser el padrino de bautizo de su sobrina», La Nación, 24 de febrero, 2016, acceso: 05 de noviembre, 2019, https://www.nacion.com/el-pais/servicios/jovengay-logro-ser-el-padrino-de-bautizo-de-su-sobrina/EJAH7PQN7RGHXMTWHXBJ6QALVQ/ story/

50. Sancho, Manuel, «Mercado no siempre entiende forma de ser de los adolescentes y desaprovecha sus compras en "tribu"», CR Hoy, 21 de noviembre, 2014, acceso: 05 de noviembre, 2019, https://archivo.crhoy.com/ mercado-no-siempre-entiende-forma-de-ser-de-los-adolescentes-y-desaprovecha-sus-compras-en-tribu/ entretenimiento/cultura/

51. Cabezas, Yaslin, «Educadores "maniatados" ante rebeldía de niños y jóvenes», CR Hoy, 20 de octubre, 2015, acceso: 05 de noviembre, 2019, https://archivo.crhoy.com/educadores-maniatados-ante-rebeldia -de-ninos-y-jovenes/nacionales/

52. Madrigal, César, «Publicación en Facebook contra bandera indigna redes sociales», La Prensa Libre, acceso: 05 de noviembre, 2019, https://www.laprensalibre.cr/Noticias/detalle/64842/publicacion-en-facebook -contra-bandera-indigna-redes-sociales

53. En este caso, si bien puede haber una separación hacia el joven por su preferencia sexual, lo que interesa es evidenciar el rol único que se le asigna y lo determina.

54. Pérez propone cuatro ámbitos sociales, el cual es la construcción normativa (desde el Derecho) de los jóvenes. En este estudio no se incluyen, ya que no fueron identificadas noticias en esta lógica dentro de la base de datos. 
a. «La juventud costarricense se encuentra en un panorama negativo frente a las oportunidades de insertarse en el mercado laboral, en un momento en el que tenemos la tasa de desempleo más alta desde la crisis de los 80 y el desempleo abierto juvenil supera el $24 \% \gg{ }^{55}$

b. «Hoy en día los ninis (un término que deriva de la frase «ni estudia ni trabaja») son más de 20 millones, tienen entre 15 y 24 años de edad y dos tercios de ellos son mujeres, de acuerdo con un nuevo estudio del Banco Mundial» ${ }^{56}$

c. «Jóvenes, de zonas urbanas y con secundaria incompleta: la cara del desempleo en Costa Rica» ${ }^{57}$

d. «Desempleo golpea a 99 mil jóvenes menores de 24 años» ${ }^{58}$

e. «Jóvenes destacan la educación como principal reto en su día» ${ }^{59}$

Este espacio es asiduamente discutido en la prensa escrita, ya que compete a dos ámbitos de la vida social como son el mundo del trabajo y la educación ¿Afuera o adentro de las instituciones formales? Es habitual en el abordaje sobre los jóvenes, como ya se vio, principalmente al hacer referencia al desempleo, la exclusión educativa y a la relacióndependencia entre ambas, donde además se asocian ciertos conceptos con los jóvenes como «ninis», crisis, desinterés y desempleo. Este ámbito se retomará más adelante.

Dejando a los jóvenes dentro-fuera de las instituciones de socialización, se pasa al segundo espacio de visibilización que se desea hacer referencia, que es la construcción de las juventudes referente al consumo de bienes simbólicos y culturales, una idealización simplificadora sobre las personas jóvenes y sus realidades. Esta noción, identificada por Pérez, invita principalmente a cuestionar la comprensión de las personas jóvenes y trascender más allá de las formas de cómo se ha «visibilizado» y «construido en la esfera pública», según sus opciones de consumo.

De esta relación juventud-consumo, se han podido encontrar notas de prensa que ilustran la premisa, en las cuales se hace una constante relación, principalmente con formas de comunicación y el consumo de tecnología, pero se vio también en relación con el consumo de grupos musicales, moda y cultura. Para muestra, los siguientes titulares de noticias periodísticas:

55. Palma, Mariela, «Opinión: Unidad para el avance de un modelo de desarrollo», Diario Extra, 29 de marzo, 2016, acceso: 05 de noviembre, 2019, http://www.diarioextra.com/Noticia/detalle/287897/ unidad-para-el-avance-de-un-modelo-de-desarrollo

56. Villareal, S., «"Ninis” varones aumentan en América Latina», Diario Extra, 19 de enero, 2016, acceso: 05 de noviembre, 2019, http://www.diarioextra.com/Noticia/detalle/281533/ninis-varones-aumentan -en-america-latina

57. Arias, Juan Pablo, «Jóvenes, de zonas urbanas y con secundaria incompleta: la cara del desempleo en Costa Rica», CR Hoy, 04 de abril , 2015, acceso: 05 de noviembre, 2019, https://archivo.crhoy.com/ jovenes-de-zonas-urbanas-y-con-secundaria-incompleta-la-cara-del-desempleo-en-costa-rica/economia/

58. Arias, Juan Pablo, «Desempleo golpea a 99 mil jóvenes menores de 24 años», CR Hoy, 16 de octubre, 2015, acceso: 05 de noviembre, 2019, https://archivo.crhoy.com/desempleo-golpea-a-99-mil-jovenes -menores-de-24-anos/economia/

59. Alvarado, Josué, «Jóvenes destacan la educación como principal reto en su día» CR Hoy, 12 de agosto, 2015, acceso: 05 de noviembre, 2019, https://archivo.crhoy.com/jovenes-destacan-la-educacion -como-principal-reto-en-su-dia/nacionales/ 
- «Teléfono inteligente es vital para 9 de cada 10 jóvenes» ${ }^{60}$

- «Mayoría de adolescentes hacen amigos por Internet» ${ }^{61}$

- «Jóvenes sienten impotencia y frustración sin su celular» ${ }^{62}$

- «Adolescentes de Costa Rica privilegian vida real antes que la digital» ${ }^{63}$

- «E1 55\% de jóvenes considera que celular es utensilio más importante de sus vidas» ${ }^{64}$

- «3 claves del éxito de Snapchat en los jóvenes» ${ }^{65}$

Las anteriores son una muestra de la relación que se hace en la esfera pública entre joven y el consumo de bienes simbólicos. Como cierre a lo planteado, se hace necesario abrir otro espacio en los escenarios de visibilización de las personas jóvenes, al menos al tomar como referencia lo que la prensa revisada durante el 2015 y 2016, y es que surge un reconocimiento sobre las personas jóvenes emprendedoras, es decir, se empiezan a hacer constantes las iniciativas que promueven el individualismo y el emprendimiento, encajando también con el constructo de jóvenes buenos. Las siguientes noticias ilustran lo referido:

a. «Un grupo de jóvenes costarricenses que se encargan de unir causas sociales con empresas, personas y organizaciones no gubernamentales, expandirá sus operaciones en Nueva York. Se trata de la empresa YOU, que se dedica a elaborar estrategias de comunicación, negocios y de responsabilidad social.» ${ }^{66}$

60. «Teléfono inteligente es vital para 9 decada 10 jóvenes», La Nación, 13 de octubre, 2015, acceso: 05 de noviembre, 2019, https://www.nacion.com/tecnologia/moviles/telefono-inteligente-es-vital-para-9-de-cada-10-jov enes/6ETMXMUIDBHS7FMFDQI476K4GU/story/

61. «Mayoría de adolescentes hace amigos por Internet», La Nación, 10 de agosto, 2015, acceso: 05 de noviembre, 2019, https://www.nacion.com/tecnologia/innovaciones/mayoria-de-adolescentes-hace-amigos -por-internet/PWDYLQ6BKFCDVKEIGYC53T7TZQ/story/

62. Ugarte, Joselyn, «Jóvenes sienten "impotencia y frustración” sin su celular», CR Hoy, 24 de octubre, 2015, acceso el 05 de noviembre, 2019, https://archivo.crhoy.com/jovenes-sienten-impotencia -y-frustracion-sin-su-celular/nacionales/

63. Vargas, Monserrat, «Adolescentes de Costa Rica privilegian vida real antes que la digital», La Nación, 28 de octubre, 2015, acceso: 05 de noviembre, 2019, https://www.nacion.com/tecnologia/redes-sociales/adolescentes-de-costa-rica-privilegian-vida-real-antes-que-la-digital/UNI7Q6OGMJBIRKKCXDHEYYV4UM/ story/

64. «E155\% de jóvenes considera que celular es utensilio más importante de sus vidas», La Nación, 16 de octubre, 2015, acceso: 05 de noviembre, 2019, https://www.nacion.com/tecnologia/moviles/el-55-de-jovenes-considera-que-celular-es-utensilio-mas-importante-de-sus-vidas/NTVCXSW7FBFSXD6WS74WYENBLE/ story/

65. «3 claves del éxito de Snapchat en los jóvenes», La Prensa Libre, 16 de abril, 2016, acceso: 05 de noviembre, 2019, http://www.laprensalibre.cr/Noticias/detalle/64866/3-claves-del-exito-de-snapchat-en-los-jovenes

66. Rodríguez, Raquel, «Emprendedores ticos abren operaciones en Nueva York», La Republica, 20 de abril, 2016, acceso: 05 de noviembre, 2019, https://www.larepublica.net/noticia/emprendedores_ticos _abren_operaciones_en_nueva_york 
b. $« 72 \%$ de ellos se consideran personas con un espíritu emprendedor» ${ }^{67}$

c. «¿Alguna vez ha soñado con tener su propio negocio? Pues David Barahona, de la empresa Neansa, lo hizo realidad. Pese a que su sueño fue estudiar periodismo, tuvo que sacar contabilidad en un colegio técnico en Cartago para empezar a trabajar desde los 18 años» ${ }^{68}$

De lo visto sobre el acontecer noticioso, no solo las miradas institucionales y los ámbitos de visibilización ${ }^{69}$ son construcciones y producciones sociales, sino que, además, se ve cómo la prensa escrita reproduce algunas de estas. En este artículo se mostrará evidencias de las recepciones de los contenidos vinculados con jóvenes, principalmente aquellos que se construyen utilizando el término «nini» (fuera de la institucionalidad deseable) y las réplicas por parte de los receptores, mediante comentarios desde las redes sociales en las versiones digitales de los diarios. Se busca en la reflexión, en última instancia, el acercamiento al modo cognoscitivo procesual, mencionado anteriormente.

En este punto de la discusión se han relacionado los aportes de Pérez con lo encontrado en las noticias, pero es importante de recapitular que hay un interés particular de referirse a la comprensión de los jóvenes buenos y malos y los jóvenes dentro-fuera de las instituciones de socialización. Es trascendente esta correspondencia, ya que la condición de estar dentro o fuera del trabajo, o de la escuela, en buena parte determina a los sujetos como buenos o malos, relación peligrosa como lo exponen Gutiérrez, Martínez y Pacheco. ${ }^{70}$

Como es la intención, seguidamente se desarrolla el apartado en el cual se presentan comentarios que devienen de noticias relacionadas con «ninis». En este caso, los «ninis» son la condición de estar fuera de las instituciones de socialización y se verá cómo, a su vez, hay una tendencia a pensarse como los malos en el entramado social.

\section{Comentarios obtenidos}

En este apartado se mostrarán réplicas de quienes reciben contenidos referentes a las personas jóvenes, propiamente se verá el peso del uso del término «nini» en algunos ejemplos del compilado. A modo de ejemplo y retomando la tendencia sobre el rol único, el siguiente texto es una réplica o comentario sobre una de las noticias antes mostradas, que versa sobre una manifestación de jóvenes anarquistas:

67. Vargas, Monserrat, «Jóvenes ‘del milenio’en Costa Rica persiguen su felicidad antes del dinero», La Nación, 05 de julio, 2015, acceso: 05 de noviembre, 2019, https://www.nacion.com/ciencia/aplicaciones-cientificas/ jovenes-del-milenio-en-costa-rica-persiguen-su-felicidad-antes-del-dinero/6RPD3EN435ECHJ5P6YNETEHQMY/story/

70. Delgado, Ronny, «Emprendedor: Uno no nace para ser maceta de corredor», La Prensa Libre, 27 de marzo, 2016, acceso: 05 de noviembre, 2019, https:/www.laprensalibre.cr/Noticias/detalle/63010/ emprendedor:-uno-no-nace-para-ser-maceta-de-corredor

71. Pérez menciona otro ámbito como lo son las normas jurídicas, que definen sujetos de derechos, pero en la base de datos no se encontró ninguna información para valorarlo dentro de este espacio.

70. Gutiérrez García, «Los jóvenes que...» 
«(...) INDIGNANTE como este reguero de VAGOS anarquistas... Esta gente que no hace NADA POR UN COSTA RICA MÁS SEGURO con qué DERECHO tienen ellos... ¿Dónde están los padres de estos VAGOS ??? » $(\mathrm{sic})^{71}$

Estas dos condiciones - no estudiar, ni trabajar- se articulan entre sí y explicarían, en parte, las reproducciones negativas generadas por el término «nini», ya que se habla de jóvenes que están fuera de las instituciones de socialización -sin profundizar en la exclusión de la institucionalidad-y que, por tanto, la tendencia es considerar a este grupo excluido como «malos», sobre los cuales recaen otras valoraciones, como ser un grupo peligroso, propenso a las drogas, vagos, etcétera.

Esta ligereza en el uso de los términos en la prensa escrita es de mucha atención porque se debe tener claridad de, por lo menos, tres premisas propuestas por Stuart Hall ${ }^{72}$, a saber:

a. La prensa escrita es un vehículo de información intencionada que se envía a la sociedad.

b. La información de la prensa escrita estructura relaciones e ideas sobre determinado fenómeno.

c. La prensa escrita tiene un reconocimiento colectivo que legitima la información.

Sobre estos alcances, Hall se ha pronunciado, definiendo:

Estos códigos son los medios por los cuales el poder y la ideología significan en los discursos particulares. Ellos remiten los signos a los «mapas de significados» en los cuales cualquier cultura está clasificada; y estos «mapas de significados» tienen un amplio espectro de significados sociales, prácticas, usos, poder e intereses «escritos» en ellos. ${ }^{73}$

Con la intención de mostrar más de estas representaciones y el uso del término «nini», se muestra seguidamente otro comentario:

«Como quien dice, quieren tirársela rico y recibir todo a manos llenas si tan siquiera moverse del sillón, pues actualmente la tónica es pasar viendo tele o jugando Wii. Casi que hasta la comida hay que llevársela porque si no, ni desayunan, ni almuerzan y menos cenan» (sic) ${ }^{74}$

Este comentario se toma después de un artículo de opinión, que reproduce la idea de que la exclusión educativa y el desempleo son causa de que los jóvenes no quieren hacer nada. En este mismo sentido, se encontró un uso frecuente del término «ninis» en otros artículos periodísticos, como:

- «Ninis» aumentan en una Costa Rica con mercado laboral complejo ${ }^{75}$

71. Comentario desde red social, sección de comentarios en laprensalibre.cr

72. Hall citado por Carballo Chaves, «El discurso mediático sobre el sistema educativo público costarricense» (tesis de licenciatura en Sociología, Universidad de Costa Rica 2009).

73. Ibid., 46 .

74. Comentario desde red social, sección de comentarios en diarioextra.com

75. Rojas, Pablo «"Ninis” aumentan en una Costa Rica con mercado laboral complejo», CR Hoy, 19 de mayo, 2016, acceso: 05 de noviembre, 2019, https://archivo.crhoy.com/ninis-aumentan-en-una-costa-rica -con-mercado-laboral-complejo/nacionales/ 
Esta nota aporta algunos datos del Estado de la Nación como, por ejemplo, las tipificaciones y diferenciaciones dentro de este «grupo» en al menos cuatro, como lo son:

a. Desempleados.

b. Estudiantes en educación no formal que no estudian ni trabajan.

c. Mujeres que trabajan en labores domésticas que no estudian formalmente ni trabajan de forma remunerada.

d. Al «núcleo nini», que define como los que no estudian ni trabajan pero que tampoco desean hacerlo.

Además, el artículo cita otros datos del observatorio de la Coyuntura Económica Social, de la Universidad Nacional (UNA), que presenta la distribución de 184561 personas jóvenes definidas como «ninis», que se desglosan así: 32\% busca empleo, $29 \%$ no estudia ni trabaja por atender obligaciones familiares y 39\% no trabaja, no estudia ni atiende obligaciones familiares.

Otros ejemplos de textos periodísticos son:

- Empléate llegó a Guanacaste, región con más de 8 mil «ninis» ${ }^{76}$

- «Ninis» varones aumentan en América Latina ${ }^{77}$

Este último caracteriza a los «ninis» latinoamericanos según el Banco Mundial, que señala un panorama negativo para los jóvenes en el caso de Centro América, Colombia y México, al vincularlos con el crimen organizado y donde «prácticamente el 60 por ciento de los ninis de la región provienen de hogares pobres o vulnerables en el 40 por ciento más pobre de la distribución del ingreso».$^{78}$

Ante esto, surge una primera tendencia en los comentarios en redes sociales, la cual considera que, los jóvenes sin estudiar o trabajar, es llanamente porque no quieren hacerlo. El siguiente cuadro ilustra con algunas expresiones:

76. Barquero, Karla, «Empléate llegó a Guanacaste, región con más de 8 mil "ninis"», CR Hoy, 27 de mayo, 2016, acceso: 05 de noviembre, 2019, https://archivo.crhoy.com/ empleate-llego-a-guanacaste-region-con-mas-de-8-mil-ninis/nacionales/

77. Villareal, S. «"Ninis" varones aumentan en América Latina», Diario Extra, 19 de enero, 2016, acceso: 05 de noviembre, 2019, http://www.diarioextra.com/Noticia/detalle/281533/ ninis-varones-aumentan-en-america-latina-

78. Ibid. 


\section{CUADRO 1}

La exclusión laboral y educativa es responsabilidad del individuo: expresiones en comentarios

Ejercito de delincuentes (sic)

Vagos, desocupados, viciosos, zánganos (sic)

Los que tomaran el mando del departamento de robos asaltos y violaciones (sic)

Una incubadora para vicios (sic)

Buscadores de dinero fácil (sic)

Están ocupados robando su casa (sic)

Fuente: Elaboración propia.

Como se argumentó anteriormente, esta lógica de hablar de «ninis» trae en sí la tendencia de considerar a este grupo excluido como «malos», a lo que hay que sumarle aconteceres noticiosos en los que explícitamente se categoriza negativamente a las personas jóvenes, como el siguiente titular:

- Jóvenes, los «protagonistas en el teatro de la violencia» ${ }^{79}$

Publicado por el diario digital CR Hoy, en su desarrollo se valida la idea que los jóvenes son los principales actores cuando de delitos se trata. Para este fin se toma el criterio del vice ministro de Paz Víctor Barrantes, quien dice no esconder la preocupación ante el escenario en el que viven los jóvenes entre 15 y 30 años en el territorio costarricense y, además, habla de las estadísticas que dicen que el $45 \%$ de las víctimas por homicidios en el país corresponde a personas entre los 15 y los 24 años, grupo que sobresale cuando se valora la edad de la población penitenciaria y las tasas de desempleo.

Otro de los titulares tiene un desarrollo particular. En la construcción del mensaje, el protagonista es un joven de 22 años, vecino de una zona rural costarricense al norte de la provincia de Heredia, quien desde hace año y medio no se encontraba estudiando ni trabajando. Esta persona dice: «En un momento estuve trabajando, pero por problemas tuve que renunciar. De hecho, ahorita matriculé en el colegio nocturno porque por unos problemas no pude sacar el colegio $\rangle^{80}$, a lo que el medio agrega que encaja a la perfección con la categoría de «nini».

El problema que la noticia plantea es que en el país, según un informe de la Contraloría General de la República (CGR) en 2014, en el país hay deficiencias en las políticas públicas destinadas a atender a los jóvenes entre los 12 y 24 años que no hacen nada y que

79. Solano, Johel, «Jóvenes, los "protagonistas en el teatro de la violencia"», CR Hoy, 20 de agosto, 2016, acceso: 05 de noviembre, 2019, https://www.crhoy.com/nacionales/jovenes-los-protagonistas -en-el-teatro-de-la-violencia/

80. Ugarte, Joselyne, «Joven de 22 años vive bajo el estigma de ser un "nini”», CR Hoy, 23 de enero, 2016, acceso: 05 de noviembre, 2019, https://archivo.crhoy.com/joven-de-22-anos-vive-bajo-el-estigma-de-ser-un-nini/ nacionales/ 
representan el $19 \%$ de la población costarricense; es decir, en ese año eran cerca de 201 mil «ninis» y esboza interrogantes que proponen considerarlos más allá de la estadística y comprender su situación en la cotidianidad concreta. Las preguntas planteadas son: ¿Cómo vive un «nini» su condición? Y ¿realmente son todas las personas vagas o indiferentes a lo que la sociedad y las cifras revelan sobre ellas?

Definido el protagonista y el problema, la meta de la noticia pareciera ser el profundizar en el problema de los «ninis», por lo que acude a expertos en el tema. Lo primero son las estadísticas del Banco Mundial, que aportan el dato de que cerca de 20 millones de latinoamericanos se encuentran en esta situación de no estudiar ni trabajar y, además, acuden a un experto en población de la UNA, Guillermo Acuña, quien confirma los datos y suma que este grupo es el resultado de malas políticas públicas y la institucionalidad del país, al afirmar que dos ámbitos sociales (educación y empleo) no les resuelven el proyecto a las personas jóvenes o son excluidos de estos.

Por otro lado, la noticia aporta ciertas consideraciones intencionadas en las que individualiza la responsabilidad nuevamente a quienes están sin estudiar y sin trabajar, para lo cual se utiliza el criterio de una profesional en ciencias psicológicas quien dice que todo ser humano tiene la capacidad de buscar oportunidades, a pesar de las condiciones socioeconómicas y, además, vuelve a responsabilizar a los padres por esta situación.

Lo interesante de este caso es que, por un lado, se aportan datos y valoraciones de expertos que hablan sobre la complejidad del sector de la población joven que no estudia y no trabaja, así como las razones institucionales, políticas y económicas que permean este fenómeno; pero, al final del documento se vuelve al criterio de que es una decisión personal, para lo cual se utiliza a una persona profesional que refuerza la idea. Lo que interesa para lo que se viene mostrando es ver el efecto de esta noticia en los receptores, donde parece calar más la versión de la responsabilidad individual y familiar del problema. Para complementar lo anterior, se muestra la siguiente tendencia: 
CUADRO 2

La exclusión laboral y educativa es responsabilidad del individuo: expresiones en comentarios

Si juntamos este montón de vagos con las drogas, es un tema serio (sic)

Andar todo el dia de raid, vender un par de purillos para financiarse el autoconsumo que trabajar y asi pasar los dias, y los años (sic)

Que los ninis siempre son las victimas, aaaaah siii pero tatuages polos y buenas tennis no les falta (sic)

Son el producto de un sistema que les dice que no se esfuercen porque de todos modos pasan de año (sic)

Por que no los llaman por su nombre: vagos? (sic)

La culpa de los ninis la tienen los propios ninis, no sus padres, ni el estado (sic)

La mayor parte del tiempo se trata de vagancia, falta de vision y metas, falta de disciplina, falta de compromiso. Oportunidades se encuentran si se buscan con pasión y con ansias de superarse (sic)

Cuántos de esos ninis andarán buscando pokemones (sic)

Luego, esperan que el resto de la sociedad les solucione la problemática generada a raíz de sus decisiones equivocadas (sic)

Los jóvenes, con excepciones, quieren todo fácil (sic)

Lo permite con el facilismo y el probrecitismo (sic)

Ahhhh nooooo, pero como dicen los psicólogos, no hay que molestarlos, no hay que obligarlos, ellos solos se va enderesando, esos son los verdaderos culpables!!! (sic)

AHORA ESTOS VAGABUNDOS QUE NO ESTUDIAN NI NADA LE QUIEREN HECHAR LA CULPA AL ESTADO, QUE SE JODAN (sic)

Fuente: Elaboración propia.

En este sentido, lo neurálgico es que en la mayoría de los casos, por más que las noticias muestran algunos datos duros o dan un aporte sensibilizando respecto a la problemática y causas estructurales de esta realidad, los usos de un concepto como «nini» termina responsabilizando individualmente a cada uno de los jóvenes o a los padres de familia, como se muestra en la tercera tendencia: 


\section{CUADRO 3}

Exclusión laboral y educativa es responsabilidad de los padres de familia: expresiones en comentarios

Todo esto es culpa de los padres, quienes no les inculcan responsabilidad a los hij@s (sic)

Si bien el trabajo para los menores es un problema de «derechos», al menos se les debe imponer responsabilidades en el hogar (sic)

Pero muchas veces la culpa la tienen los padres que los prefieren en casa que anden haciendo nada productivo (sic)

Pero como dicen los psicólogos, no hay que molestarlos, no hay que obligarlos, ellos solos se va enderesando, esos son los verdaderos culpables!!! garrote y juete parejo a ese poco de maricones mimados para que aprendan (sic)

Fuente: Elaboración propia.

El término «nini» es un juicio donde solo existe una responsabilidad individual o familiar para estar sin estudiar o trabajar; además, estar bajo estas condiciones es un estigma cargado de representaciones.

En las conclusiones se dará respuesta a las interrogantes iniciales que motivaron este artículo.

El objetivo general de esta indagación fue establecer la comprensión que se tiene sobre las personas jóvenes en medios de comunicación; para esto, se parte que en la producción de un mensaje está quién lo emite y la comprensión de quién lo recibe, por lo que en este artículo se asumen los dos componentes y se trabaja en los contenidos del mensaje emitido, de la mano con la teoría sobre juventud y se analiza la recepción de los contenidos.

De esta forma se exponen desde los contenidos de los mensajes la reproducción de ciertos ámbitos sociales atribuidos sobre las personas jóvenes y espacios de visualización de esta misma población y, por otro lado, se contrasta con las construcciones de quiénes leen los contenidos, donde sobresalen estereotipos sobre la población en edad joven. Se considera que estos resultados (emisión-recepción) tienen un cimento importante en la falta de comprensión crítica y estructural de las condiciones de este grupo poblacional prevalente en América Latina, donde Costa Rica no es la diferencia.

\section{Conclusiones}

Como quedó evidenciado, hay algunos ámbitos que se asocian directamente con juventud, como el educativo, el laboral y el consumo de bienes simbólicos, que en algunos definen al individuo y al grupo; asimismo, temas en los que se inscribe esta población (consumo de drogas, delitos y violencia), correspondientes con algunos términos o conceptos comienzan a presentarse e intentan hacer referencia a las problemáticas o 
escenarios que enmarcan a esta población, como es el caso del ya revisado constructo del «nini».

Si bien el término pudo tener cabida en alguna coyuntura específica, sucede que empieza a ser utilizado para homogeneizar la situación de las personas entre menos de 15 años y los 30 que están excluidos del sistema educativo y laboral. Este rango etario se corresponde, a su vez, con la etapa de la juventud, por lo que al hacer uso indiscriminadamente del término, se hace inmediata referencia a los jóvenes y viceversa. Ante esto, hay que recordar las consideraciones desde la postura de la representaciones sociales, que producen creencias, atribuciones de causalidad, estereotipos. Ahora, esto es más complejo cuando se construye un mensaje al utilizar un término impreciso y que, además, apela a problemáticas sociales como drogas, delitos, desempleo y de esta forma es enviado y recibido en el colectivo, lo que trae como consecuencia el surgimiento y legitimación de estereotipos o ideas preconcebidas sobre determinados grupos y sus realidades.

Este panorama habla de las respuestas que acaecen de un término impreciso, acrítico y utilizado con frecuencia para hablar de ciertos fenómenos y que de ninguna forma se ocupa o explica las condiciones del porqué de un grupo importante de la población están excluidas. Entonces, ¿por qué es importante trabajar la construcción mediática de las personas jóvenes en la prensa escrita costarricense? Es importante en tanto se puede hacer lectura de las construcciones y comprensiones que se tiene sobre la juventud y hacer un pronunciamiento crítico.

En el contexto costarricense, al igual que en la región centroamericana, hay una disputa por espacios como el laboral y el educativo. En Costa Rica, donde solo 19,4 \% de la población posee algún pregrado o grado de educación superior, estas desigualdades que estratifican a la población sin duda se representa en condiciones binarias: los que cumplen con lo deseado y los otros «responsables individuales» de su condición.

En el momento en que no se discute de fondo sobre empleo, educación y desigualdad, se pasa a una omisión de derechos y la comprensión de la juventud apunta a lecturas recreacionistas «higienista, que tuvo sus orígenes en el fin del siglo XIX en Estados Unidos, como una forma de frenar el surgimiento de males sociales (delincuencia, alcoholismo, libertinaje y otros vicios), pero, a la vez, como una forma de control social de ese nuevo tiempo libre, de descanso y de posible ociosidad, que tenía la masa trabajadora como consecuencia de la reducción de la jornada laboral». ${ }^{81}$

¿Cuáles son los vacíos o comprensiones respecto de los «ninis» en la prensa escrita? Es un término frecuente pero indistinto que arrastra prejuicios sobre el grupo en cuestión; se responsabiliza a los individuos, es de mucho cuidado las representaciones por parte de la prensa sobre determinado grupo, ya que el mensaje puede omitir las condiciones estructurales de la población y mostrarse únicamente lo fenoménico y así será recibido el mensaje.

81. Rodrigo Elizalde, «Resignificación del ocio: aportes para un aprendizaje transformacional», Polis, Revista Latinoamericana 9 (25-2010): 437-460, acceso: 5 de noviembre, 2019, https://www.redalyc.org/ pdf/305/30512376026.pdf 
¿Qué recepción tiene los contenidos noticiosos sobre las personas jóvenes? De lo revisado en el periodo establecido y desde la base de datos analizada, los comentarios utilizados evidencian la recepción con valoraciones muy negativas, ya que estas respuestas surgen únicamente de contenidos referentes a problemáticas que se presentan sobre la población joven. En la región centroamericana, como en Costa Rica, se mostró, a partir de otras investigaciones, que hubo una relación al referirse a problemas sociales (maras, desempleo, deserción escolar, inseguridad) con personas jóvenes, por lo que se puede afirmar que hay una reproducción del discurso acusador de que las personas jóvenes son culpables de la violencia, que justificó en ciertos momentos la mano dura en la región centroamericana.

Por último, el análisis de medios de prensa escrita es una vía accesible para acercarse a la representación de las personas jóvenes y de la juventud en la sociedad costarricense. Se puede seguir profundizando en las elaboraciones mediáticas y que principalmente que la crítica sirva para trascender los roles únicos, las atribuciones negativas y profundizar en las problemáticas que afectan a este sector de la población.

\section{ABSTRACT \\ Youth in Costa Rican newspapers: «And if we put together all these good-for-nothings, it's a serious issue» ${ }^{82}$}

This article deals with the discussion of social representation of young people in Costa Rican newspapers. It develops an analysis of the ways young people are seen; their reproduction in mass media and the considerations from those who get news on this particular population. It is a qualitative study with descriptive scope that has as primary sources several digital newspapers and all other content regarding this age group between 2015 and 2016. It delves into the use of the term «nini» in the development of news and the creation of stereotypes that surround this construct by those who produce the information and those who receive it.

Key words: Youth, mass media, sociology of communication, stereotypes, daily news.

RÉSUMÉ

Les jeunes et la presse écrite costaricienne: «Et si l’on réunit les fainéants avec les drogues, cela est un sujet sérieux» ${ }^{83}$

Cet article traite de la discussion des représentations sociales sur les personnes jeunes et la presse écrite au Costa Rica. On analyse les points de vue depuis lesquelles les jeunes sont construits, sa reproduction dans les moyens de communication et les considérations de ceux qui reçoivent les actualités sur cette population. Il s'agit d'une étude qualitative et descriptive qui se fonde sur des sources primaires telles que divers journaux digitaux costariciens et tous les contenus qui concernent les jeunes entre les années 2015 et 2016. Dans la discussion, on fait aussi une analyse approfondie de l'utilisation du terme «nini» dans le développement des nouvelles et la création des stéréotypes autour de ce concept par les personnes qui produisent l'information et celles qui $\mathrm{y}$ accèdent.

82. Translation of the expression "Y si juntamos este montón de vagos con las drogas, es un tema serio»

83. Traduit de l'expression «Y si juntamos este montón de vagos con las drogas, es un tema serio» 
Mots-clés: Jeunesse, moyens de communication, sociologie de la communication, stéréotypes, presse d'information quotidienne.

\section{Referencias bibliográficas}

Artículo «El $55 \%$ de jóvenes considera que celular es utensilio más importante de sus vidas». La Nación, versión digital, 16 de octubre, 2015. Acceso: 11 de noviembre, 2019. http://www.nacion.com/tecnologia/ celulares/telefono-comunicacion-adolescentes-America_Latina_0_1518448212.html

Artículo «Teléfono inteligente es vital para 9 de cada 10 jóvenes». La Nación, versión digital, 13 de octubre, 2015. Acceso: 11 de noviembre, 2019. http://www.nacion.com/tecnologia/celulares/Telefono-vital-jovenes_0_1517848213.html

Artículo «Mayoría de adolescentes hace amigos por Internet». La Nación, versión digital, 10 de agosto, 2015. Acceso: 11 de noviembre, 2019. https://www.nacion.com/tecnologia/innovaciones/ mayoria-de-adolescentes-hace-amigos-por-internet/PWDYLQ6BKFCDVKEIGYC53T7TZQ/story/

Artículo «3 claves del éxito de Snapchat en los jóvenes». La Prensa Libre, versión digital, 12 de abril, 2016. Acceso: 11 de noviembre, 2019. http://www.laprensalibre.cr/Noticias/ detalle/64866/3-claves-del-exito-de-snapchat-en-los-jovenes

Aliaga Sáez, Felipe y Gerardo Escobar Monje. «El imaginario social del joven en Chile. Una aproximación teórica al concepto del joven problema». Aposta. Revista de Ciencias Sociales (31. 2006): 1-17. Acceso: 11 de noviembre, 2019. http://www.apostadigital.com/revistav3/hemeroteca/aliaga2.pdf

Alvarado, Josué. "Jóvenes destacan la educación como principal reto en su día». CR Hoy, versión digital, 12 de agosto, 2015. Acceso: 11 de noviembre, 2019. http://www.crhoy.com/archivo/ jovenes-destacan-la-educacion-como-principal-reto-en-su-dia/nacionales/\#

Arias, Juan Pablo. «Desempleo golpea a 99 mil jóvenes menores de 24 años». CR Hoy, versión digital, 16 de octubre, 2015. Acceso: 11 de noviembre, 2019. http://www.crhoy.com/archivo/ desempleo-golpea-a-99-mil-jovenes-menores-de-24-anos/economia/\#

Arias, Juan Pablo. «Jóvenes, de zonas urbanas y con secundaria incompleta: la cara del desempleo en Costa Rica». CR Hoy, versión digital, 4 de abril, 2015. Acceso: 11 de noviembre, 2019. http://www.crhoy.com/ archivo/jovenes-de-zonas-urbanas-y-con-secundaria-incompleta-la-cara-del-desempleo-en-costa-rica/ economia/\#

Avalos, Ángela. «Padres sufren viacrucis para rehabilitar a hijos adictos». La Nación, versión digital, 21 de setiembre, 2015. Acceso: 11 de noviembre, 2019. http://www.nacion.com/nacional/salud-publica/Padresenfrentan-crucis-rehabilitar-adictos_0_1513448666.html

Barquero, Karla. "Empléate llegó a Guanacaste, región con más de 8 mil "ninis"». CR Hoy, versión digital, 27 de mayo, 2015. Acceso: 11 de noviembre, 2019. http://www.crhoy.com/archivo/ empleate-llego-a-guanacaste-region-con-mas-de-8-mil-ninis/nacionales/\#

Barquero, Karla. «Jóvenes intoxicados, incidente frecuente en festejos populares.» CR Hoy, versión digital, 25 de diciembre, 2015. Acceso: 11 de noviembre, 2019. http://www.crhoy.com/archivo/ jovenes-intoxicados-incidente-frecuente-en-festejos-populares/nacionales/\#

Borunda Escobedo, José Eduardo. «Juventud lapidada: el caso de los ninis». Nóesis. Revista de Ciencias Sociales y Humanidades. 120-143 (2013). Acceso: 11 de noviembre, 2019. http://www.redalyc.org/articulo.oa?id=85927875006

Cabezas, Yaslin. «Educadores "maniatados" ante rebeldía de niños y jóvenes». CR Hoy, versión digital, 20 de octubre, 2015. Acceso: 11 de noviembre, 2019. http://www.crhoy.com/ educadores-maniatados-ante-rebeldia-de-ninos-y-jovenes/ 
Cabezas, Yaslin. «Seguidores de Iron Maiden comienzan a acampar para el concierto».CR Hoy, versión digital, 22 de febrero, 2016. Acceso: 11 de noviembre, 2019. http://www.crhoy.com/archivo/ seguidores-de-iron-maiden-comienzan-a-acampar-para-el-concierto/entretenimiento/\#

Carballo-Chaves, P. «El discurso mediático sobre el sistema educativo público costarricense». Tesis para optar por el grado de licenciatura en Sociología. Ciudad Universitaria Rodrigo Facio. Universidad de Costa Rica. 2009.

Cascante, Sharon. «Jóvenes amarran y arrastran tortuga baula en Limón». La Prensa Libre, versión digital, 29 de marzo, 2016. Acceso: 11 de noviembre, 2019. http://www.laprensalibre.cr/Noticias/detalle/63217/ video:-jovenes-amarran-y-arrastran-tortuga-baula-en-limon

Centeno Orozco, Rebeca. «Discursos públicos y construcción de ciudadanía: ¿poder de los medios de comunicación?». Orbis. Revista Científica Ciencias Humanas 10 (28. 2014): 120-133. Acceso: 11 de noviembre, 2019. http://www.redalyc.org/articulo.oa?id=70930408007

Chinchilla, Sofía. «150.000 jóvenes ni estudian ni trabajan en Costa Rica». La Nación, versión digital, 23 de abril, 2016. Acceso: 11 de noviembre, 2019. http://www.nacion.com/nacional/educacion/Numero-jovenesnini-pais-baja_0_1556444369.html

Dautrey, Philippe. «La invención de una categoría: los NiNis. El caso mexicano». RIPS. Revista de Investigaciones Políticas y Sociológicas, julio-diciembre, 103-122 (2014). Acceso: 11 de noviembre, 2019. http:// www.usc.es/revistas/index.php/rips/article/view/1901

Delgado, Ronny. "6 claves para saber si su hijo sufre "bullying"». La Prensa Libre, versión digital, 23 de febrero, 2016. Acceso: 11 de noviembre, 2019. http://www.laprensalibre.cr/Noticias/ detalle/59168/552/6-claves-para-saber-si-su-hijo-sufre-bullying

Delgado, Ronny. «Emprendedor: Uno no nace para ser maceta de corredor». La Prensa Libre, versión digital, 27 de marzo, 2016. Acceso: 11 de noviembre, 2019. https://www.laprensalibre.cr/Noticias/detalle/63010/ emprendedor:-uno-no-nace-para-ser-maceta-de-corredor

Duarte Quapper y Littin Menz. Niñas, niños y jóvenes: Construyendo imágenes en la prensa escrita. Chile: Asociación Chilena pro Naciones Unidas, 2002.

Editorial «¿Y los padres qué estamos haciendo?». Diario Extra, versión digital, 2 de marzo, 2017. Acceso: 11 de noviembre, 2019. http://www.diarioextra.com/Noticia/detalle/326435/y-los-padres-que--estamos-haciendo

Editorial «Tratamiento de la adicción juvenil». La Nación, versión digital, 22 de septiembre, 2015. Acceso: 11 de noviembre, 2019. http://www.nacion.com/opinion/editorial/Tratamiento-adiccion-juvenil_0_1513648630. html

Elizalde, Rodrigo. «Resignificación del ocio: aportes para un aprendizaje transformacional». Polis, Revista Latinoamericana 9 (25): 437-460.

Granados, Greivin. «50 mil jóvenes no estudian ni trabajan en Costa Rica». La Prensa Libre, versión digital, 16 de agosto, 2016. Acceso: 11 de noviembre, 2019. https://www.laprensalibre.cr/Noticias/ detalle/80710/50-mil-jovenes-no-estudian-ni-trabajan-en-costa-rica

Granados, Greivin. «Están calificados dentro del grupo de los "ninis"». La Prensa Libre, versión digital, 16 de agosto, 2016. Acceso: 11 de noviembre, 2019. https://www.laprensalibre.cr/Noticias/ detalle/80710/50-mil-jovenes-no-estudian-ni-trabajan-en-costa-rica

Gutiérrez García, Raúl Alejandro; Martínez Martínez, Kalina Isela; Pacheco Trejo, Aymé Yolanda «Los jóvenes que no estudian ni trabajan en México». Enseñanza e Investigación en Psicología (2014). Acceso: 11 de noviembre, 2019. www.redalyc.org/pdf/292/29238007007.pdf

Lemus, Leslie. «Guatemala: repensando el vínculo entre juventud y violencia en la posguerra». LiminaR. Estudios Sociales y Humanísticos XVI (2. 2018): 45-59. Acceso: 11 de noviembre, 2019. http://www.scielo.org. $\mathrm{mx} /$ scielo.php?script $=$ sci_arttext $\&$ pid $=$ S1665-80272018000200045 
Madrigal, Cesar. «Publicación en Facebook contra bandera indigna redes sociales». La Prensa Libre, versión digital, 11 de abril, 2016. Acceso: 11 de noviembre, 2019. http://www.laprensalibre.cr/Noticias/deta1le/64842/publicacion-en-facebook-contra-bandera-indigna-redes sociales?fb_comment_id=98473289827 9129_984865338265885\#f20d06fa8b6f31c

Mayorga Rojel y Alberto, Carlos del Valle Rojas. «Análisis de la configuración semiótica de Chile y Perú en la prensa escrita». Quórum Académico 5 (1. 2008): 17-40.

Mejía Navarrete, Julio. «Medios de comunicación y violencia. Los jóvenes pandilleros de Lima». Espacio Abierto 14 (3. 2005): 389-404. Acceso: 11 de noviembre, 2019. http://www.redalyc.org/articulo.oa?id=12214304

Mena Araya, Aarón. «TIC y medios de comunicación». Repositorio Kerwá, Universidad de Costa Rica (2016): 339-372. Acceso: 11 de noviembre, 2019. http://www.kerwa.ucr.ac.cr/bitstream/handle/10669/30116/ cap8_2016.pdf?sequence=1\&isAllowed=yMexico.pdf

Moreira, A. «La educación de los hijos, derechos y deberes». CR Hoy, versión digital, 2 de febrero, 2016. Acceso: 11 de noviembre, 2019.úhttp://www.crhoy.com/opinion-la-educacion-de-los-hijos-derechos-y-deberes/ opinion/el-lector-opina/

Nuñez, Pedro. Las juventudes disputadas. Aportes para un campo en construcción. Compilado por Diego Beretta. Argentina: Editorial de la Universidad del Rosario, 2015.

Palma, Mariela. «Unidad para el avance de un modelo de desarrollo». Diario Extra, versión digital, 29 de marzo, 2016. Acceso: 11 de noviembre, 2019. http://www.diarioextra.com/Noticia/detalle/287897/ unidad-para-el-avance-de-un-modelo-de-desarrollo

Pérez Islas, José Antonio. «Ser joven en México: conceptos y contextos». Educación y Ciudadanía A.C. (2000). Acceso: 11 de noviembre, 2019. http://www.educiac.org.mx/pdf/Biblioteca/Juventud_e_ Identidad/019SerJoven_en_Mexico.pdf

Pérez Islas, José Antonio. Teorías sobre la juventud. Las miradas de los clásicos. Coordinado por José Antonio Pérez Islas, Mónica Valdez González y María Herlinda Suarez Zozaya. México D.F.: Porrúa, 2008.

Recio, Patricia. «Joven gay logró ser el padrino de bautizo de su sobrina». La Nación, versión digital, 24 de febrero, 2016. Acceso: 11 de noviembre, 2019. http://www.nacion.com/nacional/religion/Joven-convertirsepadrino-negativa-sacerdote_0_1544645621.html

Rodríguez, Raquel. «Emprendedores ticos abren operaciones en Nueva York». La República, versión digital, 20 de abril, 2016. Acceso: 11 de noviembre, 2019. https://www.larepublica.net/noticia/ emprendedores_ticos_abren_operaciones_en_nueva_york

Rojas, Lady. «Resentimientos, desamores y bullying hacen a los jóvenes caer en depresión y tristeza». CR Hoy, versión digital, 6 de diciembre, 2013. Acceso: 11 de noviembre, 2019. http://www.crhoy.com/archivo/ resentimientos-desamores-y-bullying-hacen-de-los-jovenes-personas-deprimidas-y-desesperadas/

Rojas, Pablo. "Ninis" aumentan en una Costa Rica con mercado laboral complejo». CR Hoy, versión digital, 19 de mayo, 2016. Acceso: 11 de noviembre, 2019. http://www.crhoy.com/archivo/ ninis-aumentan-en-una-costa-rica-con-mercado-laboral-complejo/nacionales/

Ross, Amy. «País tiene en abandono la salud mental de sus adolescentes». La Nación, versión digital, 31 de agosto, 2013. Acceso: 11 de noviembre, 2019. http://www.nacion.com/nacional/Pais-abandono-saludmental-adolescentes_0_1363263689.html

Saintout, Florencia. Los jóvenes en la Argentina: Desde una epistemología de la esperanza. Buenos Aires: Universidad Nacional, Quilmes Editorial, 2013.

Sancho, Manuel. «Mercado no siempre entiende forma de ser de los adolescentes y desaprovecha sus compras en "tribu"». CR Hoy, versión digital, 21 de noviembre, 2014. Acceso: 11 de noviembre, 2019. http://www. crhoy.com/archivo/mercado-no-siempre-entiende-forma-de-ser-de-los-adolescentes-y-desaprovecha-suscompras-en-tribu/entretenimiento/cultura/\# 
Solano, Johel. «Jóvenes, los "protagonistas en el teatro de la violencia"». CR Hoy, versión digital, 20 de agosto, 2016. Acceso: 11 de noviembre, 2019. https://www.crhoy.com/nacionales/ jovenes-los-protagonistas-en-el-teatro-de-la-violencia/\#

Téllez Velasco, Daniel. «Jóvenes nini y profesionistas titi: la estratificación letrada del desempleo». El Cotidiano, septiembre-octubre, 83-96. Acceso: 11 de noviembre, 2019. http://www.redalyc.org/articulo. oa?id=32519776009

Ugarte, Joselyn. «Jóvenes sienten "impotencia y frustración" sin su celular». CR Hoy, versión digital, 24 de octubre, 2016. Acceso: 11 de noviembre, 2019. http://www.crhoy.com/archivo/ jovenes-sienten-impotencia-y-frustracion-sin-su-celular/nacionales/\#

Ugarte, Joselyn. «MEP cuenta 153 denuncias por casos de abuso o acoso sexual». CR Hoy, versión digital, 23 de febrero, 2019. Acceso: 11 de noviembre, 2019. http://www.crhoy.com/archivo/ mep-cuenta-153-denuncias-por-casos-de-abuso-o-acoso-sexual/nacionales/\#

Ugarte, Joselyne. «Con rompope, vino y cervezas jóvenes ingresan al mundo del alcohol». CR Hoy, versión digital, 21 de septiembre, 2015. Acceso: 11 de noviembre, 2019. http://www.crhoy.com/archivo/ con-rompope-vino-y-cerveza-jovenes-ingresan-al-mundo-del-alcohol/nacionales/\#

Ugarte, Joselyne. "Joven de 22 años vive bajo el estigma de ser un "nini"». CR Hoy, versión digital, 23 de enero, 2016. Acceso: 11 de noviembre, 2019. http://www.crhoy.com/archivo/ joven-de-22-anos-vive-bajo-el-estigma-de-ser-un-nini/nacionales/\#

Ugarte, Joselyne. «Tras el licor y marihuana, jóvenes usan medicinas como droga». CR Hoy, versión digital, 5 de octubre, 2015. Acceso: 11 de noviembre, 2019. http://www.crhoy.com/archivo/ tras-el-licor-y-marihuana-jovenes-usan-medicinas-como-droga/nacionales/\#

Vargas, Monserrat. «Adolescentes de Costa Rica privilegian vida real antes que la digital». La Nación, versión digital, 28 de octubre, 2015. Acceso: 11 de noviembre, 2019. http://www.nacion.com/tecnologia/redessociales/Adolescentes-ticos-privilegian-vida-digital_0_1520847923.html

Vargas, Monserrat. «Jóvenes 'del milenio' en Costa Rica persiguen su felicidad antes del dinero». La Nación, versión digital, 5 de julio, 2015. Acceso: 11 de noviembre, 2019. http://www.nacion.com/vivir/ciencia/ Jovenes-milenio-persiguen-felicidad-dinero_0_1497850243.html

Vega Jiménez, Patricia. «La investigación sobre comunicación en Centroamérica (1980-2015)». Anuario Electrónico de Estudios en Comunicación Social "Disertaciones" 9(2. 2016): 117-138. Acceso: 11 de noviembre, 2019. https://revistas.urosario.edu.co/index.php/disertaciones/article/view/4299

Vergara Quintero, María del Carmen. «La naturaleza de las representaciones sociales». Revista Latinoamericana de Ciencias Sociales, Niñez y Juventud 6 (1. 2008): 55-80. Acceso: 11 de noviembre, 2019. http://www. redalyc.org/pdf/773/77360103.pdf

Villareal, S. «"Ninis”varones aumentan en América Latina». Diario Extra, 19 deenero, 2016. Acceso: 11 denoviembre, 2019. http://www.diarioextra.com/Noticia/detalle/281533/ninis-varones-aumentan-en-america-latina-

Zúñiga Núñez, Mario. Pensar a los jóvenes: Más allá de modelos o monstruos. Costa Rica: Departamento Ecuménico de Investigación DEI, 2010. 